\title{
BMJ Open Is overseas volunteering beneficial to the NHS? The analysis of volunteers' responses to a feedback questionnaire following experiences in low-income and middle-income countries
}

Daniel Yeomans, ${ }^{1}$ Grace Le, ${ }^{2}$ Hemant Pandit, ${ }^{2,3}$ Chris Lavy ${ }^{1,2}$

To cite: Yeomans D, Le G, Pandit $\mathrm{H}$, et al. Is overseas volunteering beneficial to the NHS? The analysis of volunteers' responses to a feedback questionnaire following experiences in low-income and middleincome countries. BMJ Open 2017;7:e017517. doi:10.1136/ bmjopen-2017-017517

- Prepublication history for this paper is available online. To view these files please visit the journal online (http://dx.doi. org/10.1136/bmjopen-2017017517).

$\mathrm{HP}$ and $\mathrm{CL}$ contributed equally.

Received 1 May 2017

Revised 18 July 2017

Accepted 8 August 2017

CrossMark

${ }^{1}$ Oxford University Hospitals NHS Foundation Trust, Oxford, UK ${ }^{2}$ Nuffield Department of Orthopaedics, Rheumatology and Musculoskeletal Sciences, University of Oxford, Oxford, UK ${ }^{3}$ Leeds Institute of Rheumatic and Musculoskeletal Medicine, University of Leeds, Leeds, UK

Correspondence to

Dr Daniel Yeomans;

danyeomans@gmail.com

\section{ABSTRACT}

Introduction Locally requested and planned overseas volunteering in low-income and middle-income countries by National Health Service (NHS) staff can have benefits for the host or receiving nation, but its impact on the professional development of NHS staff is not proven. The Knowledge and Skills Framework (KSF) and Leadership Framework (LF) are two tools used by employers as a measure of individuals' development. We have used dimensions from both tools as a method of evaluating the benefit to NHS doctors who volunteer overseas.

Methods 88 NHS volunteers participating with local colleagues in Primary Trauma Care and orthopaedic surgical training courses in sub-Saharan Africa were asked to complete an online self-assessment questionnaire 6 months following their return to the UK. The survey consisted of questions based on qualities outlined in both the KSF and LF.

Results 85 completed responses to the questionnaire were received. In every KSF domain assessed, the majority of volunteers agreed that their overseas volunteering experience improved their practice within the NHS. Selfassessed pre-course and post-course scores evaluating the LF also saw a universal increase, notably in the 'working with others' domain.

Discussion There is a growing body of literature outlining the positive impact of overseas volunteering on NHS staff. Despite increasing evidence that such experiences can develop volunteers' essential skills, individuals often find it difficult to gain support of their employers. Our study, in line with the current literature, shows that overseas volunteering by NHS staff can provide an opportunity to enhance professional and personal development. Skills gained from volunteering within international links match many of the qualities outlined in both KSF and LF, directly contributing to volunteers' continued professional development.

\section{INTRODUCTION}

Volunteer work in low and middle-income countries (LMICs) by National Health Service (NHS) staff is increasing. Much of this work takes place in formal partnerships or links,
Strengths and limitations of this study

- High response rate with broad base of participants provides us with a representative sample.

- Questions asked in survey are directly attributable to qualities outlined in both the Knowledge and Skills Framework and Leadership Framework.

- It is possible that our results may be skewed based on the assumption that only those volunteers with positive experiences replied to the survey.

which are organised collaborations between UK healthcare organisations and healthcare organisations in LMICs. The Tropical Health Education Trust reports that over 6 years they have worked with 157 partnerships, involving over 1700 NHS health workers in 26 countries, and training over 50000 overseas health workers. ${ }^{1}$ Where this is done appropriately and in partnership, there are recognised benefits to LMIC; however, what is less clear is whether there is any benefit to the NHS.

We searched PubMed using the following terms: [volunteer*] AND [NHS]. ${ }^{2}$ We found 141 publications; however, on review only 3 had any relevance to this study. We also searched for non-indexed (grey) material by using the same search terms on Google. This produced nine additional relevant publications.

Jones et al have reviewed the available literature on benefit to the NHS of working overseas. ${ }^{3}$ This review, based on governmental papers and experiential studies, concluded that the skills acquired during volunteering are directly transferable to service delivery within the NHS. In 2007, Lord Crisp published an in-depth analysis of work carried out by international health links across the UK. ${ }^{4}$ His report recommends that staff involvement with international development brings clear benefits to 
the UK and NHS and should be endorsed by governmental organisations. This subsequently prompted the Department of Health (DoH) to outline support for the development of international healthcare partnerships ${ }^{56}$ In their response, they state that working in challenging environments provides healthcare professionals with the opportunity to gain leadership as well as managerial and educational skills, which are both beneficial and transferable to the NHS. The All Party Parliamentary Group on Global Health have also provided guidance on volunteering; that when done well, the NHS gains in key domains such as communication, leadership skills and self-understanding. ${ }^{5}$ Clinical staff in particular reportedly gain from experiences in resource poor settings and return with renewed interest in service integration, commissioning and team work. The Academy of Medical Royal Colleges have also issued a statement in support of overseas work and stress the importance of implementing a mechanism whereby overseas volunteering can be formally recognised. ${ }^{78}$

The NHS Knowledge and Skills Framework (KSF) is currently used to monitor development of NHS staff, as well as their professional performance at work. ${ }^{9}$ It comprises a series of dimensions relevant to working in the NHS, for example: health safety and security, communication, personal and people development, and equality and diversity. In addition to the KSF, the NHS Leadership Academy has a self-assessment tool for its Leadership Framework (LF) ${ }^{10}$ This assesses a standardised set of domains which underpin relevant attributes required for successful leadership within the NHS. ${ }^{11}$ These include: demonstrating personal qualities, working with others, managing services, improving services, setting direction, creating the vision and delivering the strategy. Both the LF and the KSF self-report forms have been used by NHS Trusts in staff appraisal.

In 2012, a qualitative study by Longstaff interviewing 28 staff from seven NHS trusts in the North of England using KSF and LF as a foundation concluded that staff members volunteering in international links developed a higher level of skill in both frameworks. ${ }^{12} 78 \%$ of volunteers interviewed claimed that overseas experience 'gives you professional development you don't get anywhere else', 90\% claimed that the experience had been 'good for their personal development' and 96\% said that the 'reputation of the NHS involvement could only be enhanced by international health links'.

Following the above study in 2015, Longstaff worked with Health Education England (HEE) and published a comprehensive toolkit to help doctors and other healthcare workers to review their overseas work and provide formal and accredited evidence on this work for the purposes of appraisal and revalidation. ${ }^{13}$ This resource, based on skills outlined in the KSF and LF, was agreed by NHS employers and the DoH to be a satisfactory form of documentation for Continuing Professional Development and appraisal.

In this paper, we set out to use KSF and LF to analyse the experience and feedback from NHS volunteers who participated in training healthcare workers in LMICs in sub-Saharan Africa.

\section{METHODS}

COSECSA Oxford Orthopaedic Link (COOL) is a partnership programme between the College of Surgeons of East, Central and Southern Africa (COSECSA) and the University of Oxford..$^{14}$ The programme's aim is to strengthen research and training in trauma and musculoskeletal impairment in the 10 COSESCA countries (Burundi, Ethiopia, Kenya, Tanzania, Uganda, Rwanda, Malawi, Mozambique, Zambia and Zimbabwe). The programme has delivered over 60 training courses since it started in 2012. These include 1-week orthopaedic surgery courses, trauma care provider courses and trauma care instructor courses, using the Primary Trauma Care (PTC) training system. ${ }^{16} 17$ During these courses, the UK NHS faculty teaches alongside local faculty so that both groups develop collegiality and also learn from each other. The courses include lectures, tutorials with small groups and practical workshops on a range of topics in trauma and elective orthopaedics. In total, more than 3000 participants attended the courses.

Over a 4-year period (from 1 April 2012 to 31 August 2016), 88 UK NHS volunteers made 155 visits to Africa to work with local trainers to run the COOL trauma and orthopaedic training courses across the 10 COSECSA countries. Six months following their return to the UK, the NHS volunteers were sent by email an electronic questionnaire using Survey Monkey. ${ }^{18}$ In addition to demographic information, the survey contained a self-assessment form that mapped onto domains in both the KSF as well as the LF. The electronic form of this survey was the only method whereby volunteers were able to respond. Volunteers were given the option of not giving their name and filling the form anonymously.

The survey consisted of two main sections; first, volunteers were asked questions based on the KSF dimensions: health, safety and security, communication, personal and people development, and equality and diversity. Volunteers were asked to agree or disagree with a set of eight statements (as outlined in table 1) related to their development during the experience. In the second section, participants were asked a series of seven questions with reference to each of the NHS LF domains: demonstrating personal qualities, working with others, managing services, improving services, setting direction, creating the vision and delivering the strategy. ${ }^{11}$ For each domain, candidates were asked to score their perceived ability on a scale of $1-10$, for before and after their volunteering experience.

Two further questions examined the volunteers' views on the possible negative effects of overseas work on the NHS and their involvement with global health since returning to the UK. All responses were anonymised and the data were analysed using Microsoft Excel. All participants surveyed gave consent for their answers to be included in this analysis. 
Table 1 Responses to statements related to National Health Service (NHS) Knowledge and Skills Framework (KSF)

\begin{tabular}{|c|c|c|c|c|c|}
\hline KSF domain & Statement & Agree & Don't know & Disagree & $\begin{array}{l}\text { Not } \\
\text { specified }\end{array}$ \\
\hline Communication & $\begin{array}{l}\text { I have learnt to communicate better with those for } \\
\text { whom English is not a first language }\end{array}$ & 69 & 8 & 6 & 2 \\
\hline Communication & I have improved in involving audience participation & 69 & 8 & 6 & 2 \\
\hline $\begin{array}{l}\text { Personal } \\
\text { and people } \\
\text { development }\end{array}$ & $\begin{array}{l}\text { I have been able to practice and learn from the } \\
\text { leadership role I was given }\end{array}$ & 73 & 5 & 4 & 2 \\
\hline $\begin{array}{l}\text { Personal } \\
\text { and people } \\
\text { development }\end{array}$ & $\begin{array}{l}\text { I have reflected and recognise ways I can improve } \\
\text { my teaching }\end{array}$ & 81 & 0 & 2 & 2 \\
\hline $\begin{array}{l}\text { Personal } \\
\text { and people } \\
\text { development }\end{array}$ & $\begin{array}{l}\text { I have learnt to understand the needs of those in } \\
\text { other cultures better }\end{array}$ & 82 & 0 & 1 & 2 \\
\hline $\begin{array}{l}\text { Health, safety } \\
\text { and security }\end{array}$ & $\begin{array}{l}\text { I have a different attitude to NHS health, safety and } \\
\text { security than I did before the course }\end{array}$ & 48 & 11 & 24 & 2 \\
\hline $\begin{array}{l}\text { Equality and } \\
\text { diversity }\end{array}$ & $\begin{array}{l}\text { I have a better understanding of equality and } \\
\text { diversity in the NHS than I did before the course }\end{array}$ & 45 & 11 & 27 & 2 \\
\hline
\end{tabular}

\section{RESULTS}

\section{Demographics}

We sent the questionnaire in the form of a URL link to our survey monkey site to all 88 NHS professionals who volunteered on PTC and COOL orthopaedic courses between 1 April 2012 and 31 March 2016. Some NHS professionals will have volunteered on more than one course. We received 85 responses, 40 giving their names and 45 remaining anonymous. Of these, the largest group was consultant anaesthetists $(n=28)$ with the second most common specialty being consultant surgeons $(\mathrm{n}=20)$ (figure 1). All participants completed questions regarding KSF; however, six did not complete the second section, which involved LF. Thirty-one volunteers took annual leave for their time overseas with 22 taking study leave. Other methods of making time to travel included:

\section{Occupation of Volunteers}

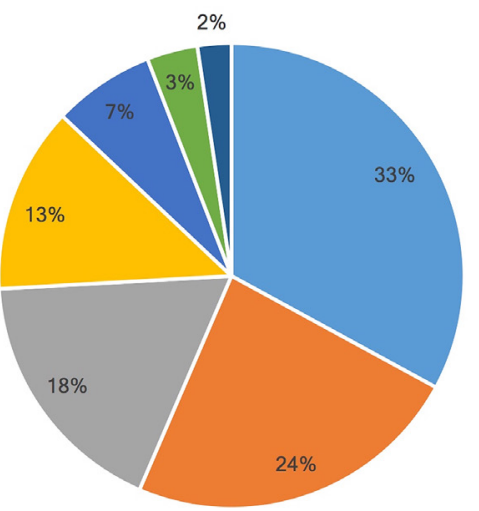

$$
\begin{aligned}
& \text { - Consultant Anaesthetist } \\
& \text { " Consultant Surgeon } \\
& \text { " Unspecified } \\
& \text { " Surgical Registrar } \\
& \text { - Emergency Department Consultant } \\
& \text { " Anasthetic Registrar } \\
& \text { - Emergency Department Registrar }
\end{aligned}
$$

Figure 1 Occupation of volunteers completing survey. zero-hour contracts, part time, professional leave, retired, time shifting, unpaid leave and time in lieu.

\section{NHS KSF}

In every KSF domain, the majority of volunteers agreed that the experience had improved their practice (table 1). The highest proportion of these was in personal and people development, where 82/85 (96\%) volunteers agreed that the experience had enabled them to gain a greater understanding of the needs of those in other cultures. The most equivocal change was in equality and diversity, where $45 / 85$ (53\%) agreed that the experience had enabled them to gain a greater understanding of equality and diversity within the NHS.

\section{NHS LF}

Self-assessed ratings submitted following the course relating to the NHS LF saw a universal increase when comparing precourse and postcourse averages (table 2). The most significant increase came in the 'working with others' domain where, on average, volunteers felt they were better equipped to develop networks, build and maintain relationships as well as working better within a team. In addition, the volunteers felt that their participation in COOL's courses helped them in many other domains including planning resources, creating vision and delivering strategy.

Figure 2 displays the volunteer's awareness of the possible negative impact of their volunteering work on the NHS. Figure 3 illustrates activities volunteers have participated in since return to the UK. For the ease of data collection, in both questions, respondents chose from a preformulated list of options. 
Table 2 Self-rating scores for statements related to National Health Service (NHS) Leadership Framework

\begin{tabular}{llll}
\hline & \multicolumn{1}{c}{$\begin{array}{c}\text { Postcourse } \\
\text { Statement }\end{array}$} & $\begin{array}{l}\text { Precourse average } \\
\text { (scores out of 10) } \\
\text { out of 10) }\end{array}$ & \% Change \\
\hline $\begin{array}{l}\text { My personal qualities (self-awareness, self-management, self- } \\
\text { development and acting with integrity) }\end{array}$ & 7.21 & 7.67 & 6.38 \\
$\begin{array}{l}\text { Working with others (developing networks, building and } \\
\text { maintaining relationships, encouraging contribution and working } \\
\text { within teams) }\end{array}$ & 7.02 & 7.94 & 13.11 \\
$\begin{array}{l}\text { Managing services (planning, managing resources, managing } \\
\text { people and managing performance) }\end{array}$ & 6.73 & 7.58 & 12.63 \\
$\begin{array}{l}\text { My ability to improve or develop NHS services (ensuring } \\
\text { patient safety, critically evaluating, encouraging innovation and } \\
\text { facilitating transformation) }\end{array}$ & 6.56 & 7.14 & 8.84 \\
$\begin{array}{l}\text { Setting direction (identifying the contexts for change, applying } \\
\text { knowledge and evidence, making decisions and evaluating } \\
\text { impact) }\end{array}$ & 6.71 & & \\
$\begin{array}{l}\text { Creating the vision (developing the vision for the organisation, } \\
\text { influencing the vision of the wider healthcare system, } \\
\text { communicating the vision and embodying the vision) }\end{array}$ & 6.26 & 7.34 \\
$\begin{array}{l}\text { Delivering the strategy (framing the strategy, developing the } \\
\text { strategy, implementing the strategy and embedding the strategy) }\end{array}$ & 6.24 & 7.05 \\
\hline
\end{tabular}

\section{DISCUSSION}

To date, analysis of overseas volunteering has primarily focused on the benefits to the host or receiving nation. However, there is increasing evidence that such experiences also have a positive impact on the NHS itself. Our study provides evidence that skills gained through overseas volunteering match many of the criteria outlined in the NHS KSF and LF. Such frameworks were designed specifically to monitor the development of UK-based healthcare professionals. ${ }^{9}$ Our findings are thus in agreement with previous studies and support the theory that overseas volunteering positively impacts on NHS staff.

Skills gained in domains such as personal and people development were particularly marked. $96 \%$ of responders agreed that the experience had allowed them to better understand the needs of those in other cultures. This may

\section{Negative Impact on the NHS}

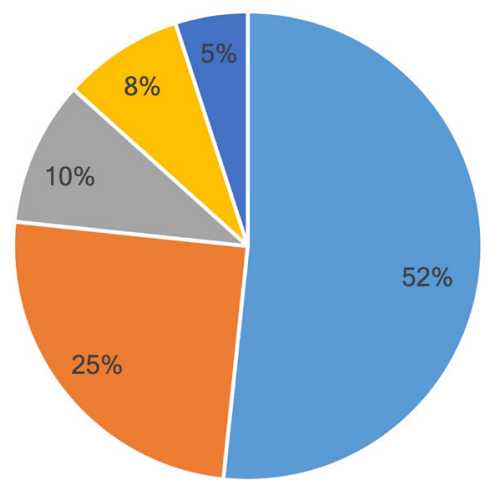

$=$ Financial (31)
$=$ Loss of staff (15)
$=$ Opportunity (6)
$=$ Health and Security (5)
- Reputational (3)

Figure 2 Possible negative impacts of volunteering on the National Health Service (NHS). be, in part, due to the specific aim of the COOL courses, to deliver education tailored specifically to the needs of LMICs. By adapting skills learnt in NHS hospitals to the needs of a LMIC, volunteers were able to gain a deeper understanding of the healthcare system and trauma burden in LMICs. The experience also provided participants with an opportunity to reflect on their own practice within the NHS and how best their skills could be used in a different, and often challenging, environment. This finding is in line with other literature, outlining personal and people development to be the domain where volunteers are set to gain the most. ${ }^{12}$

KSF highlights the importance of a supportive atmosphere for learning and development within the employees' area of work. In our study, 95\% of responders agreed that they had reflected and recognised ways in which their teaching could be improved. The structure of the PTC course may have facilitated this, as visiting UK instructors train local instructors to deliver trauma training and subsequently mentor and support them as they teach local healthcare workers. This cascading method gives a feeling of fulfilment and satisfaction to many of the NHS trainers and develops their teaching skills and helps the courses towards becoming self-sustainable. This structure also provides the opportunity to execute different teaching methods while also learning from the sessions delivered by local healthcare workers. Teaching skills learnt overseas, in unfamiliar circumstances, are directly transferable to UK work. Indeed, a number of participants reported they have taken teaching methods learnt from the course into their NHS practice. The extent to which teaching has become an integral part of any healthcare partnership is highlighted in the DoH 


\section{Activities Since Returning to the UK}

Not done anything related to global healthcare

Booked another overseas course

Become involved in another overseas course

Begun to set up a new overseas project or hospital link

Attended global health conferences/ meetings

Encouraged my colleagues to get involved overseas

Shared my experience with others

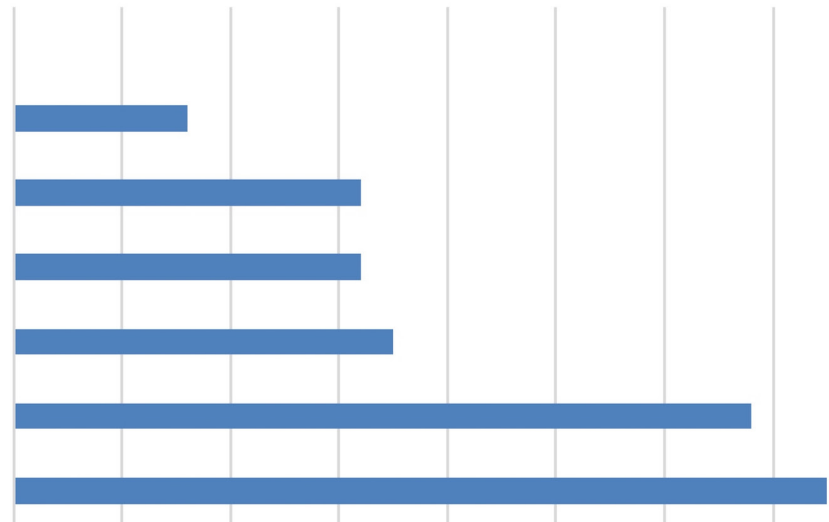

$\begin{array}{lllllllll}0 & 10 & 20 & 30 & 40 & 50 & 60 & 70 & 80\end{array}$

Figure 3 Activities volunteers have participated in since returning to the UK.

publication, Engaging in Global Health, where six health partnership case studies specify teaching as a key feature in their overseas work. ${ }^{19}$

The response rate is $85 / 88$ or $96 \%$ if we assume that all responses are from different people, as we had 85 responses and there were 88 volunteers. However, it is certainly possible that some of the 45 anonymous responses may have come from the same person as many of the volunteers did several visits. Unfortunately, the software we used does not allow us to give unique identifiers to responses and we wanted to allow responders to have anonymity if they wished. Even if we assume that every anonymous responder completed two surveys, our response rate becomes $63 / 88$ or $72 \%$ which is still high for such surveys. We credit this high response rate to the enthusiasm experienced by volunteers after the course and also to our encouragement on the importance of giving feedback when we gave precourse orientation and planning.

The NHS LF seeks to define a key set of qualities, related to good leadership, to which all NHS staff members should aspire. It is based on the principle that leadership need not only come from those at the head of an organisation, but acts of leadership should be encouraged from all members. ${ }^{11}$ The so-called 'shared' leadership is especially important in healthcare, where tasks are complex and highly interdependent. In our cohort, on average, candidates scored themselves higher in every domain assessed. The most marked increase being in working with others when volunteers scored themselves an average of $13 \%$ higher following the course. This domain includes: teamwork, encouraging contribution, developing networks and building relationships. It is possible that the challenges faced while volunteering overseas, including unfamiliar environments, language barriers and cultural differences provide a unique opportunity to develop these skills.
Although this paper provides substantial evidence for the positive impact on the NHS of international work, it is also important to consider negative implications. From our survey, 33 respondents felt one such negative aspect was financial. This unfortunately had no further break down but could refer to a number of financial implications both for individual volunteers and NHS as an organisation. Individually volunteers could have lost out financially by having to take unpaid or annual leave. From an organisational level, it may also implicate a financial cost to the NHS through the employment of locum work for time absent, or lost clinical activity by the volunteer. More research is required to outline financial implications and other barriers to volunteering overseas.

Our data come from doctors working across the UK, although it is limited to the medical specialties involved with the care of trauma and orthopaedic patients (see figure 1). This is due to the scope of the COOL and PTC courses. We do however feel it is reasonable to assume that health partnerships involving other specialties would demonstrate similar benefits to the NHS. By issuing the questionnaire to volunteers who had volunteered to participate in healthcare partnerships, we may be selecting for those who are set to gain more from such experiences.

Our data support other similar studies in finding that overseas volunteering can be very beneficial to NHS doctors, both personally and professionally. ${ }^{312} 20$ Using characteristics outlined in both KSF and LF, we have shown that skills gained during overseas volunteering are also recognised as valuable for working within the NHS. In accordance with HEE and DoH, we support the formal recognition of overseas volunteering as part of healthcare workers' continued professional development and continued appraisal. 
Contributors HP, CL, GL and DY conceived the paper. GL and CL composed and distributed the survey, using the NHS Knowledge and Skills Framework and Leadership Framework Self-Assessment tool. DY performed data analysis. DY and $\mathrm{CL}$ wrote the first draft of the manuscript. All authors (DY, GL, HP and CL) interpreted the data, edited the manuscript and approved the final draft.

Funding The COSECSA Oxford Orthopaedic Link programme is supported by the Tropical Health Education Trust, funded through the Health Partnership Scheme, which is funded by the Department for International Development for the benefit of the UK and partner country health sectors. This work was also supported by the NIHR Biomedical Research Centre, Oxford, UK.

Competing interests None declared.

Provenance and peer review Not commissioned; externally peer reviewed.

Data sharing statement № additional unpublished data available.

Open Access This is an Open Access article distributed in accordance with the Creative Commons Attribution Non Commercial (CC BY-NC 4.0) license, which permits others to distribute, remix, adapt, build upon this work non-commercially, and license their derivative works on different terms, provided the original work is properly cited and the use is non-commercial. See: http://creativecommons.org/ licenses/by-nc/4.0/

(C) Article author(s) (or their employer(s) unless otherwise stated in the text of the article) 2017. All rights reserved. No commercial use is permitted unless otherwise expressly granted.

\section{REFERENCES}

1. "Our grants - Tropical Healthcare Education Trust (THET)." [Online]. http://www.thet.org/our-work/our-grants (accessed 20 Jun 2017).

2. "Home - PubMed - NCBI." [Online]. https://www.ncbi.nlm.nih.gov/ pubmed/ (accessed 20 Jun 2017).

3. Jones FAE, Knights DPH, Sinclair VFE, et al. "Do health partnerships with organisations in lower income countries benefit the UK partner? A review of the literature,". Global Health 2013:9:38.

4. Crisp N. "Global Health Partnerships: the UK contribution to health in developing countries." [Online]. $2017 \mathrm{http} / / / \mathrm{www}$.diamedica.co.uk/ english/documents/CrispReport.pdf (accessed 20 Jun 2017).

5. All-Party Parliamentary Group on Global Health. "Improving health at home and abroad - how overseas volunteering from the NHS benefits the UK and the world". $2015 \mathrm{http}: / / \mathrm{www}$.appg-globalhealth. org.uk/download/i/mark_dl/u/4009611296/4595360986/lmproving\% 20 Health\%20at\%20Home\%20and\%20Abroad\%20-\%20Final\% 20Report.pdf (accessed 20 Jun 2017).

6. Department of Health. The framework for NHS involvement in international development. $2010 \mathrm{http}: / /$ www.thet.org/healthpartnership-scheme/resources/the-framework-for-nhs-involvementin-international-development-1 (accessed 20 Jun 2017).
7. Association of Medical Royal Colleges. "Academy statement on volunteering: health professional volunteers and global health development". $2013 \mathrm{http} / / / w w w . a o m r c . o r g . u k / w p-c o n t e n t / u p l o a d s /$ 2016/05/AOMRC_Statement_2013-03-25_Volunteering_healthprofessionals_global_health_development.pdf (accessed 20 Jun 17).

8. "In our mutual interest - THET." [Online]. http://www.thet.org/ resource-library/in-our-mutual-interest (accessed 20 Jun 2017).

9. NHS Employers. "The NHS knowledge and skills framework - a short guide to KSF dimensions". 2006 http://www.msg.scot.nhs.uk/wpcontent/uploads/Short-Guide-to-KSF-Dimensions.pdf (accessed 20 Jun 2017).

10. NHS Leadership Academy. "The leadership framework: self assessment tool". $2012 \mathrm{http} / / /$ www.leadershipacademy.nhs. uk/wp-content/uploads/2012/11/NHSLeadership-FrameworkLeadershipFrameworkSelfAssessmentTool.pdf (accessed 20 Jun 2017).

11. NHS Leadership Academy. "Leadership Fframework, a summary". 2011 http://www.leadershipacademy.nhs.uk/wp-content/uploads/ 2012/11/NHSLeadership-Framework-LeadershipFrameworkSummary.pdf (accessed 12 Dec 2016).

12. Longstaff $B$. Innovative workforce development: the case for international health links. 2010;27 http://www.thet.org/healthpartnership-scheme/files/innovative-workforce-development-thecase-for-international-health-links

13. Health Education England. "Toolkit for the collection of evidence of knowledge and skills gained through participation in an international health project". http://www.tvwleadershipacademy.nhs.uk/sites/ default/files/ighposters/HEE\%20Toolkit\%20for\%20evidence\% 20Interactive\%20v4.pdf (accessed 20 Jun 2017).

14. COOL - COSECSA Oxford orthopaedic link [Online] https://www. ndorms.ox.ac.uk/research/global-surgery/projects/cool-training-intrauma (accessed 15 Oct 2016).

15. COSECSA - College of Surgeons of East, Central and Southern Africa. COSECSA 2017 AGM \& Scientific conference. http://www. cosecsa.org (accessed 15 Oct 2016).

16. Peter NA, Pandit H, Le G, et al. Delivering a sustainable trauma management training programme tailored for low-resource settings in East, Central and Southern African countries using a cascading course model. Injury 2016;47:1128-34.

17. Primary trauma care foundation [Online]. https://www. primarytraumacare.org/ (accessed 16 Oct 2016).

18. Survey monkey [Online]. https://www.surveymonkey.co.uk/ (accessed 18 Dec 2016).

19. Public Health Directorate. International branch "engaging in global health- the framework for voluntary engagement in global health by the UK health sector.". 2014 http://www.globalhealthexchange.co.uk/ userfiles/file/Engaging_in_Global_Health_1_.pdf (accessed 17 Oct 2016).

20. Longstaff B. "How international health links can help the NHS workforce develop,". Health Serv Reshttps://www.hsj.co.uk/howinternational-health-links-can-help-the-nhs-workforce-develop/ 5044915.article (accessed 23 Sep 2016). 